\title{
Reducing ventilator-associated pneumonia in neonatal intensive care unit using "VAP prevention Bundle": a cohort study
}

Seham F. A. Azab*, Hanan S. Sherbiny, Safaa H. Saleh, Wafaa F. Elsaeed, Mona M. Elshafiey, Ahmed G. Siam, Mohamed A. Arafa, Ashgan A. Alghobashy, Eman A. Bendary, Maha A. A. Basset, Sanaa M. Ismail, Nagwa E. Akeel, Nahla A. Elsamad, Wesam A. mokhtar and Tarek Gheith

\begin{abstract}
Background: Ventilator-associated pneumonia (VAP) is a serious health care- associated infection, resulting in high morbidity and mortality. It also prolongs hospital stay and drives up hospital costs. Measures employed in preventing ventilator- associated pneumonia in developing countries are rarely reported. In this study we tried to assess the efficacy of our designed "VAP prevention bundle" in reducing VAP rate in our neonatal intensive care unit (NICU).
\end{abstract}

Method: This prospective before-and-after study was conducted at university hospital NICU, all neonates who had mechanical ventilation for $\geq 48 \mathrm{~h}$ were eligible. VAP rates were evaluated before (phase-l) and after (phase-II) full implementation of comprehensive preventive measures specifically designed by our infection control team.

Results: Of 143 mechanically ventilated neonates, 73 patients developed VAP (51 \%) throughout the study period (2500 mechanical ventilation days). The rate of VAP was significantly reduced from $67.8 \%(42 / 62)$ corresponding to 36.4 VAP episodes/1000 mechanical ventilation days (MV days) in phase-l to $38.2 \%$ (31/81) corresponding to 23 VAP/ 1000 MV days (RR 0.565, $95 \%$ confidence interval 0.408-0.782, $p=0.0006$ ) after VAP prevention bundle implementation (phase-II). Parallel significant reduction in MV days/case were documented in post-intervention period (21.50 \pm 7.6 days in phase-I versus $10.36 \pm 5.2$ days in phase-II, $p=0.000$ ). There were a trend toward reduction in NICU length of stay ( $23.9 \pm 10.3$ versus $22.8 \pm 9.6$ days, $p=0.56$ ) and overall mortality ( $25 \%$ versus $17.3 \%, p=0.215$ ) between the two phases but didn't reach statistical significance. The commonest micro-organisms isolated throughout the study were gram-negative bacteria (63/66, $95.5 \%)$ particularly Klebsilla pneumonia (55/66, 83.4 \%).

Conclusion: Implementation of multifaceted infection control bundle resulted in reduction of VAP rate, length of stay in our NICU.

Keywords: Neonate, Ventilator-associated pneumonia, Infection

\section{Background}

Ventilator-associated pneumonia (VAP) is defined by the Center for Disease Control and Prevention (CDC) and National Healthcare Safety Network as new and persistent radiographic infiltrates and worsening gas exchange in infants who are ventilated for at least $48 \mathrm{~h}$ and who exhibit least 3 of the following criteria: temperature instability with no other recognized cause, leukopenia,

\footnotetext{
* Correspondence: Seham_Azab@yahoo.com

Faculty of Medicine, Zagazig University, 18 Omar Bin Elkhattab St, Al Qawmia, Zagazig City, Al Sharqia Governorate, Egypt
}

change in the characteristic of respiratory secretions, respiratory distress and bradycardia or tachycardia [1]. VAP is a serious complication in neonates on mechanical ventilation and account for $6.8-32.2 \%$ of health-care associated infections among neonates [2, 3]. It has a large impact on neonatal morbidity, survival, hospital costs and duration of neonatal intensive care unit (NICU) stay $[3,4]$. The effect of VAP on health care costs is especially significant in developing world, whereas most studies of VAP have been conducted in developed countries $[5,6]$. 
Prevention of VAP has been primarily achieved by the "bundle approach"; this involves the simultaneous application of several preventive strategies for all patients, often aided by tools such as checklist. In some cases there is only theoretical evidence or biologic plausibility for one or more of the elements of the bundle being effective, but application of these bundles is widely used and has been highly successful [7].

As neonates have different anatomy, physiology, underlying diseases and they undergo different invasive procedures compared with adults and older children [8], specific studies for evaluating different "VAP bundles" efficacy in preventing VAP in NICU are needed. In Egypt and other developing countries, reports on the success of VAP intervention strategies, particularly among neonates, are scarce. The aim of the present work is to assess the effectiveness of our proposed "VAP prevention bundle" in decreasing rates of neonatal VAP.

\section{Patients and methods Setting}

The present study was conducted in the NICU of Children Hospital of Zagazig University, Egypt from January 2013- March 2014. Our 23 bed NICU is staffed with certified physician $24 \mathrm{~h} /$ day, 7 days/week with a nurse-topatient ratio 1:3-1:4 depending on the patient acuity. Eight mechanical ventilators and 5 nasal continuous positive airway pressure (CPAP) are available at our unit. A neonatologist leads daily round on all NICU patients to review patient information and develop care plan.

\section{Design}

This before-and-after intervention prospective study passed through the following periods; phase-I at which VAP rate, expressed as the number of VAP episodes per 1000 mechanical ventilator days (VAP/1000 MV days) were calculated for 6 months started at January 2013. Throughout this period we reviewed and summarized recommendations by different authors and health institutes regarding strategies for prevention of health care associated infections particularly VAP. Observations were documented by our team members regarding the most prevalent practical errors that may contribute to increased risk of VAP among our mechanically ventilated neonates. Accordingly, our "VAP preventive bundle" was tailored to stress on our common errors and include common evidence-based practices recommended by previous studies and agencies [9-15].

Three months were needed (intermediate phase), started at July 2013, until education and full implementation of the bundle by our health care providers were satisfactory accomplished and their adherence rate reached $86 \%$. During this period we performed education session to discuss evidences about the pathogenesis, risk factors, danger of VAP and its sequel. Training and re-training campaigns were performed for each VAP bundle's item particularly hand hygiene, sterile handling of respiratory equipment, and proper timed mouth care. Finally, signed statement from each staff member acknowledging their understanding of the policy and the mandate to comply with it was taken, to ensure the connection between policy and practice.

\section{VAP prevention bundle}

In addition to routine infection control protocol, our designed bundle was composed of:

- Head-of-bed elevation $30^{\circ}-45^{\circ}$.

- Re-enforcement of hand hygiene practice.

- Sterile suction and handling of respiratory equipment.

- Intubation, re-intubation and endotracheal tube (ETT) suction as strictly indicated by unit protocol (document).

- Change ventilator circuit if visibly soiled or mechanically malfunctioning (document)

- Proper timed mouth care with normal saline and suction of oro-pharyngeal secretion.

- Daily evaluation for readiness for extubation to nasal continuous airway pressure (NCPAP) at morning round, and sedation vacation for sedated patient.

Written protocols were performed for strict indications of intubation, re-intubation, suctioning of ETT and change of the ventilator circuit. Documentation is needed in the patient flow sheet. Figure 1 explains the relation between the pathogenesis of VAP and our bundle strategies.

Phase-II started on October $1^{\text {st }} 2013$ for six months at which re-evaluation of VAP rate/1000 MV days were performed to assess the efficacy of our infection control bundle.

As VAP preventive bundle was part of our Quality Control Program where internal committee (registered nurses, infection control physicians) was assigned for continuous observation of adherence of our unit team with monthly report about this rate. VAP diagnosis: VAP was diagnosed by pediatrician and confirmed by attending neonatologist using criteria for less than one year established by Foglia and colleagues [7]. The criteria were as follow, neonatal patients who are mechanically ventilated $\geq 48 \mathrm{~h}$ must have new onset and persistent abnormal chest radiograph and worsening of gas exchange (desaturations, increased oxygen requirement or increased ventilator demand), and at least three of the following: temperature instability with no other recognized cause; new onset of purulent sputum, change in character of sputum, increased respiratory secretions, or increased suctioning requirement; apnea, tachypnea, nasal flaring with 


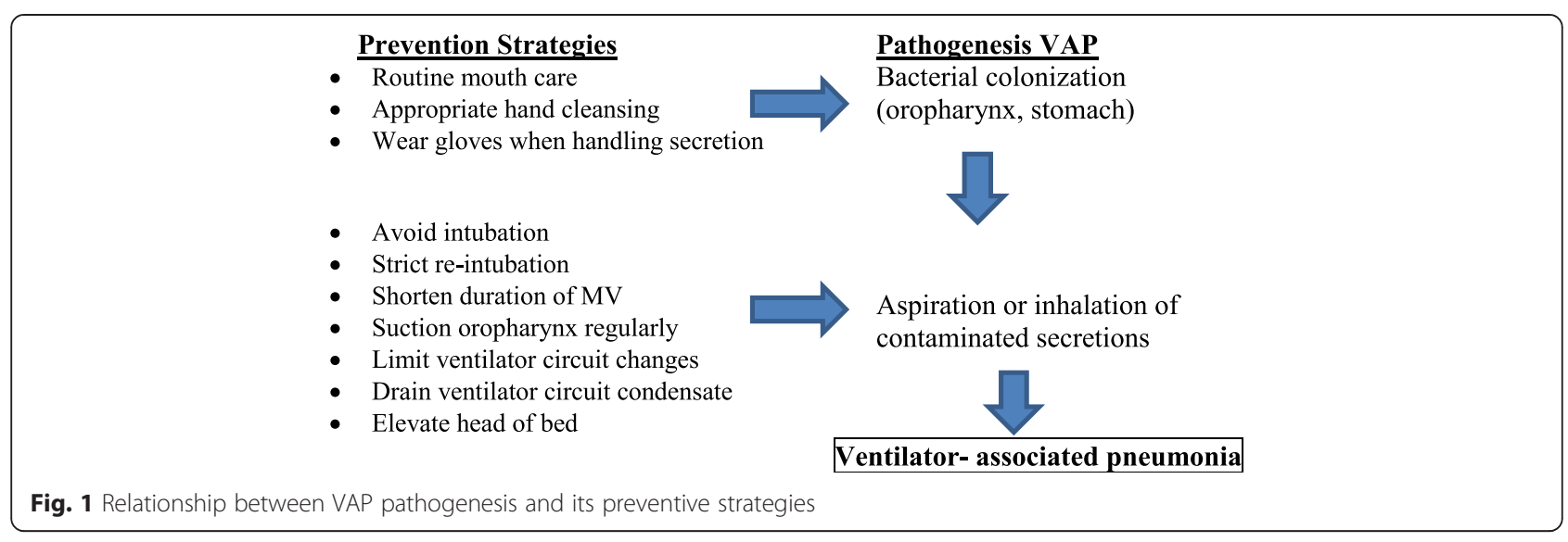

retraction of the chest wall or grunting; wheezing, rales or rhonchi; cough; and bradycardia $(<100$ beat/min) or Tachycardia ( $>170$ beat/min).

\section{Patients}

All neonates admitted to NICU during phase-I and II periods and utilized mechanical ventilation for $\geq 48 \mathrm{~h}$ were eligible. The patient demographic, date of admission, underlying disease, duration of MV, length of NICU stay, antibiotics used, and other culture positive infection while on MV were recorded for each case.

\section{Methods}

Complete blood count (CBC), C-reactive protein, blood culture and non- bronchoscopic broncho-alveolar lavage (NB-BAL) by passing $6 \mathrm{f}-8 \mathrm{f}$ sterile catheter through the endotracheal tube and wedging the airway [16] were performed for all clinically suspected VAP. The clinical microbiological laboratory analyzed the samples using Bact/Alert 3D- Biomerieux-France and provided microorganism identification followed by antibiotic sensitivity according to the isolate using Vitek MS -BiomerieuxFrance. Multidrug resistant organisms need special ABX sensitivity order.

\section{Ethics}

Informed parental consent was obtained to be eligible for enrollment into the study. The study was done according to the rules of the Local Ethics Committee of Faculty of Medicine, Zagazig University, Egypt. Our institutional review committee of ethical research approved the study.

\section{Statistical analysis}

Categorical variables were summarized as number and percent while continuous variables were expressed as mean \pm standard variation. Chi-square test and student $t$-test were used for analysis of difference for categorical and continuous variables respectively. Relative risk ratio,
$95 \%$ confidence interval, and $\mathrm{p}$ value were determined for VAP rates outcome. The level of significance was set at $\mathrm{p}<0.05$. SPSS statistical software version 16 was used for data presentation and analysis.

\section{Results}

A total of 143 neonates were enrolled in the current study as 62 cases in phase-I and 81 cases in phase-II. The two groups were comparable in term of gender, birth weight, gestational age and mode of delivery as shown in Table 1.

The leading cause for primary use of mechanical ventilation was prematurity and related complication (46/62 cases, $74.2 \%$ versus 63/81, $77.8 \%$ in phase-I and phase II respectively). Other causes such as perinatal asphyxia (6/62, $9.7 \%$ versus $11 / 81,13.6 \%)$, respiratory causes other than RDS (4/62, $6.5 \%$ versus $3 / 81,3.8 \%)$, congenital heart diseases $(5 / 62,8 \%$ versus $4 / 88,4.9 \%)$, others $(1 / 62,1.6 \%$ versus $0 \%)$ were diagnosed as primary causes for mechanical ventilation.

2500 days of mechanical ventilation were accrued during the study periods as $1154 \mathrm{MV}$ days in phase-I and 1346 MV days in phase-II. 42/62 (67.74 \%) episodes of VAP were diagnosed during the pre-intervention period with a rate of $36.4 \mathrm{VAP} / 1000 \mathrm{MV}$ days. Significant reduction in VAP incidence rate was observed after implementation of our VAP bundle, as 31/81(38.2 \%) VAP events corresponding to $23 \mathrm{VAP} / 1000 \mathrm{MV}$ days (RR 0.565, $95 \%$ CI $0.408-0.782, \mathrm{Z}$ score $3.437 \mathrm{p}=0.0006$ ) were diagnosed in phase II as displayed in Table 2.

Concomitant significant reduction in MV days/case was obvious in the post-intervention period when compared to pre-intervention one $(21.50 \pm 5.2$ days in phaseI versus $10.36 \pm 5.2$ days in phase-II, $\mathrm{p}=0.000$ ). There was a trend toward reduction in NICU length of stay $(23.9 \pm 10.3$ versus $22.8 \pm 9.6$ days in phase I and phase II respectively, $\mathrm{p}=0.56$ ) but didn't reach statistical significance. 16/62 (25.8 \%) mechanically ventilated neonates died in phase-I, 2 cases of them were related to 
Table 1 Demographic and clinical characteristics of study populations

\begin{tabular}{|c|c|c|c|}
\hline \multirow[t]{2}{*}{ Character } & \multicolumn{2}{|l|}{ Phases } & \multirow[t]{2}{*}{$p$} \\
\hline & । & $\|$ & \\
\hline Number of ventilated neonates & 62 & 81 & \\
\hline \multicolumn{4}{|l|}{ Gender (male) } \\
\hline Number & 43 & 52 & \\
\hline$\%$ & 69.3 & 64.1 & 0.52 \\
\hline \multicolumn{4}{|l|}{ Gestation age (week) } \\
\hline < 37 Number (\%) & $45(72.5)$ & $66(81.5)$ & 0.21 \\
\hline$-30-37$ & $20(32.2)$ & $34(41.9)$ & \\
\hline$-<30$ & $25(40.3)$ & $32(39.6)$ & \\
\hline > 37 Number (\%) & $17(27.5)$ & $15(18.5)$ & \\
\hline Mean \pm SD & $32.18 \pm 4.5$ & $31.73 \pm 4.3$ & 0.57 \\
\hline \multicolumn{4}{|l|}{ Birth weight (g) } \\
\hline$\leq 2500$ Number $(\%)$ & $48(77.4)$ & $63(77.7)$ & 0.99 \\
\hline$-<1500$ & $28(45)$ & $43(53)$ & \\
\hline > 2500 Number (\%) & $14(22.6)$ & $18(22.3)$ & \\
\hline Mean \pm SD & $1898 \pm 954$ & $1803 \pm 1074$ & 0.59 \\
\hline Mode of delivery (\% C/S) & 32.2 & 43.2 & 0.18 \\
\hline \multicolumn{4}{|l|}{ Days of mech. ventilation } \\
\hline Min & 5 & 5 & \\
\hline Max & 51 & 35 & \\
\hline Mean \pm SD & $21.50 \pm 7.6$ & $10.36 \pm 5.2$ & 0.000 \\
\hline \multicolumn{4}{|l|}{ Length of NICU (day) } \\
\hline Min & 7 & 10 & \\
\hline Max & 63 & 45 & \\
\hline Mean \pm SD & $23.87 \pm 10.3$ & $22.8 \pm 9.7$ & 0.56 \\
\hline Mortality Number (\%) & $16(25.8)$ & $14(17.3)$ & 0.22 \\
\hline
\end{tabular}

SD standard deviation, $C / S$ caesarian section, NICU neonatal intensive care unit

VAP caused by multidrug resistant klebsiella pneumoniae, compared to $14 / 81(17.3 \%)$ in phase-II, one of them caused by polymicrobial VAP (K. pneumoniae and Candida). The difference in overall mortality rates between the two phases didn't reach statistical significance $\left(X^{2}=1.54, \mathrm{p}=0.215\right)$.

73 VAP events were documented throughout the study, $90.4 \%(66 / 73)$ of them revealed positive isolates on culturing their NB-BAL (37/42, $88 \%$ in phase-I \&29/31, $93.5 \%$ in phase-II). Gram negative bacteria were the most commonly isolated micro-organisms $(97.2 \%$ versus $93.1 \%$ in phase-I and II respectively), klebsiella pneumoniae was the leading causative pathogen throughout the study period. No single case of Gram-positive isolates was diagnosed in phase-I cases, compared to $6.9 \%$ (2 cases) among those in phase-II. Fungus, namely Candida spp. was the single isolate from one case in phase-I, but were isolated mixed
Table 2 Ventilator-associated pneumonia rates

\begin{tabular}{lll}
\hline Item & Phases & \\
\cline { 2 - 3 } & Phase I & Phase II \\
\hline MV Neonate & 62 & 31 \\
VAP episodes & 42 & 1346 \\
MV days & 1154 & 38.2 \\
VAP \% & 67.8 & 23 \\
VAP/1000 MV days & 36.4 & \\
Relative Risk (RR) & 0.565 & \\
95 \% C.I. & $0.408-0.782$ & \\
Z score & 3.437 & \\
P & 0.0006 & \\
\hline MV mechanical ventilation, VAP ventilator-associated pneumonia, CI \\
confidence interval
\end{tabular}

with gram negative bacteria in three cases of phase-II $(10.4 \%)$ as described in Table 3.

\section{Discussion}

Advances in neonatal intensive care have improved survival among very low birth weight infants. As many of them require mechanical ventilation, VAP become a major challenge. It represents an important cause of morbidity and mortality in this high-risk population [17]. Data obtained from the current study runs in parallel with this fact as $50 \%(71 / 134)$ of mechanically ventilated neonates enrolled in the study were very low birth weight (VLBW) and $77 \%(111 / 134)$ were premature. Developmental immaturity in the neonatal immune system including greater permeability of the skin and mucus membrane, lower level of immunoglobulin, and decreased complement activity increases their susceptibility to hospital-acquired infection. Mechanical ventilation and other invasive treatment measures are very likely to increase risk of oro-pharyngeal or tracheabronchial colonization with pathogenic bacteria, VAP

Table 3 Microbiologic features of VAP pathogens

\begin{tabular}{llll}
\hline Pathogen & \multicolumn{2}{l}{ Phases } & Total \\
\cline { 2 - 3 } & Phase I & Phase II & \\
\hline Positive Culture (\%) & $37(88)$ & $29(93.5)$ & $66(90.4)$ \\
Gram-negative (\%) & $36(97.2)$ & $27(93.1)$ & $63(95.5)$ \\
- K-pneumoniae & $32(86.5)$ & $23(79.3)$ & $55(83.4)$ \\
- P-aeruginosa & $2(5.4)$ & $4(13.8)$ & $6(9)$ \\
- E-coli & $2(5.4)$ & $-(-)$ & $2(3)$ \\
Gram-positive (\%) & $-(-)$ & $2(6.9)$ & $2(3)$ \\
Fungi (\%) & $1(2.7)$ & $3^{\mathrm{a}}(10.4)$ & $4(6)$ \\
MDR (\%) & $9(24.3)$ & $8(27.6)$ & $17(25.8)$ \\
\hline
\end{tabular}

$K$ klebsiella, $P$ pseudomonas, $E$ Escherichia, MDR multiple-drug resistant, ${ }^{\text {at three }}$ cases in phase-ll showed combined $\mathrm{K}$ pneumonia and candida spp isolates 
occurs when bacterial, viral or fungal pathogens enter the sterile lower respiratory tract and lung parenchyma [18].

Several studies have shown a reduction of VAP rate after guidelines implementation into a bundle [9-15]. The power of the bundle is that it brings together several evidence-based practices that individually improve care, but when applied together, may result in an even greater improvement in the desired outcome [18]. "VAP preventive bundle" implemented in the present work was associated with statistically significant reduction in VAP rates in our NICU (36.4/1000 MV days in phase-1 versus $23 / 1000 \mathrm{MV}$ days in phase-II, $\mathrm{p}=0.0006$ ). All items involved in our proposed bundle were derived from controlled trials or health institutes recommendations for adults, children or neonatal VAP prevention [9-15].

Most adult VAP prevention bundles recommend elevation of the head of a ventilated patient's bed from 30-45 degrees to reduce the risk of aspiration of contaminated oro-pharyngeal and gastrointestinal content. Drakulovic and colleagues demonstrated that a semirecumbent position reduced the rate of clinically suspected and microbiological confirmed VAP [19]. Only one underpowered pediatric trial presented in an abstract form has evaluated this intervention and showed no effect [20]. The logic of head-of-the bed elevation is sound, it is found in almost every VAP reduction bundle and its implementation was easy and accepted by health care providers in our work.

There is unequivocal evidence that hand hygiene is the most important infection control intervention in all health care setting, but also one of the most difficult strategy to maintain. Gram negative organisms which colonize the ETT are frequently carried on the hands of the care-givers $[21,22]$. Several hand hygiene training campaigns were conducted throughout the study period, 6-steps hand washing posters were displayed on all sinks, alcohol-based hand rub solution were placed at each bedside, and in the corridor between rooms to improve compliance with hand hygiene.

Breathing circuit condensate contamination can also serve as a mechanism for the pathogenesis of VAP, the condensate that collect in the tubing should be drained away to prevent aspiration [23]. Center for Disease Control and Prevention (CDC) recommended; ensuring proper sterilization of reusable respiratory care equipment, using sterile water in humidification system, periodic drainage of condensate from the breathing circuit and hand hygiene before and after contact with respiratory equipment. CDC guidelines do not recommend changing the breathing circuit unless it is visibly soiled or mechanically malfunctioning [9]. We followed the CDC strategies regarding ventilator care in our bundle. Similarly, recent study concluded that decreasing the ventilator circuit changes from every 7 days to every 14 days has no adverse effect on the rate of VAP in NICU [24]. Yuan and his team reported that the risk factors for the development of neonatal VAP were re-intubation, frequent ETT suctioning, and the duration of mechanical ventilation [25], Tan and his fellows proved the same findings [26]. The use of non-invasive measures such as nasal CPAP and nasal prong ventilation may reduce VAP rate. In time-sequenced cohort studies, reducing days of mechanical ventilation by non-invasive respiratory support decreased VAP incidence [27, 28]. Pneumonia is less common in neonates treated with nasal CPAP when compared with those intubated on MV (1.9/1000 CPAP days versus 12.5/ $1000 \mathrm{MV}$ days, $\mathrm{p}=0.04$ ) [27]. Results from the German Surveillance System for VLBW infants supported the protected value of NCPAP against pneumonia, as its incidence was $1 / 1000$ CPAP days compared to $2.5 / 1000 \mathrm{MV}$ days [29]. In our bundle, attending physician should assess, on daily base, the readiness of every mechanically ventilated neonate for weaning to NCPAP and every effort was done to wean them as soon as possible.

Center for Disease Control and Prevention (CDC) recommended a comprehensive oral hygiene program for mechanically ventilated patient [9]. A meta- analysis by Pineda and colleagues showed reduction in VAP among adult patients treated by decontamination with oral chlorhexidine [30]. Similar protective results were concluded by meta-analysis by Chlebichi and Safdar in which chlorhexidine rinse was used [31]. Neonates are likely at greater risk for aspiration of contaminated oral secretion, because endotracheal tubes used to ventilate them are un-cuffed [18]. As chlorhexidine gluconate is not approved for infants less than 2 months, timed mouth care with normal saline and oro-pharyngeal suction were included in our bundle.

The criteria defined by Foglia and his colleagues were used throughout the present study periods to ensure uniformity of the results. The CDC/NHSN (National Health safety Network) proposed protocol clarification in July 2013, at which leukocytosis ( $>15.000$ WBC's) or leucopenia ( $<4000$ WBC's) and shift to left ( $>10 \%$ band forms) were added [32]. VAP rates has been reported from both developed and developing countries, the National Healthcare Safety Network reported that VAP rate in level III NICUs of US hospital in 2010 were in the range 0.4-1.4/1000 MV days [33]. In the International Nosocomial Infection Control Consortium, the mean rate from 36 NICUs around the world between January 2004-December 2009 was 9.0/1000 MV days [34]. In the German Nosocomial Infection Surveillance System, the mean VAP rate was 5.5/1000 MV days [29]. On the other hand, in 55 intensive care units of 8 developing countries between 2002-2005, the overall VAP rate was 24.1/1000 MV days ranging from 10.0-52.7/ 1000 MV days between units [35]. Data from Asian 
countries suggested an incidence rate varying from 3.5$46 / 1000 \mathrm{MV}$ days in the newborn period [36]. VAP rate in our study during the post-intervention period, 23/1000 MV days, was comparable to that in developing countries, but still significantly higher than the benchmark (1.5/1000 MV days) in developed countries. The lack of respiratory therapists, overcrowding in hospital, and relatively low nurse-to-patient ratio in our country's NICUs may explain such disparity. In addition, conduct of rigorous hospitalacquired infection surveillance on a multicenter collaborative network level by NICUs in most developed countries is a major factor in the gap. Significant reduction in mean mechanical ventilation days/case were achieved in our neonates in the post-intervention period, an important goal especially in premature to reduce the hazards of MV in such population. However, reduction in MV days was not associated with similar reduction in length of NICU stay, a finding which is expected when dealing with neonates particularly premature, as NICU stay is dependent on several factors mainly; the baby's gestational age, severity of underlying illness and hospital course of which, healthcare associated infection is an important factor.

The overall mortality rate among our cases showed a trend toward reduction during the post-intervention period, but didn't reach statistical significance (17.3\% in phase-II versus $25.8 \%$ in phase-I, $\mathrm{p}=0.215$ ). As we did not match patient to detect adjusted attributable mortality, it is not possible to conclude that the reduction in mortality is attributable to the decrease in VAP rate.

The predominant pathogen of VAP in our study was bacteria, Gram negative bacteria outnumbered Gram positive types. Similar finding was shown in Yuan and colleague work [25] and Xie and team trial [37], while Staphylococcus aureus and $P$. aeruginosa were the most frequently identified pathogen in VAP in western pediatric populations [38, 39]. The difference in bacterial spectrum between ours and that reported from western countries may be due to varied practices, especially antibiotic selection. Exposure of NICU patients to different antibiotics favors selection and subsequent colonization with different pathogens that may leads to VAP. Awareness of local microbiological surveillance data on hospital-acquired infection can improve the selection of appropriate therapy. Even-though, the incidence of VAP was reduced with bundle implementation in our NICU, there was no significant difference in the incidence of multi-drug resistant organisms, probably due to resistant of health care providers to follow strict antibiotics use as advised by many infection control specialist [40].

The small sample size was one of our limitations in this study; we suggest that multicenter approaches may be necessary to attain larger sample sizes and to evaluate feasibility/cost-effectiveness. Finally, future longitudinal cohort studies are recommended to validate the current findings taking into consideration the rate or level of adherence during the program.

\section{Conclusion}

This study provided characterization of VAP in an Egyptian NICU. It demonstrated that a bundle of infection control practices can effectively reduce the occurrence of VAP during neonatal ventilation. This "VAP prevention bundle" can be extended to other NICU in Egypt and other low-income countries.

\begin{abstract}
Abbreviations
VAP: Ventilator-associated pneumonia; NICU: Neonatal intensive care unit; VLBW: Very low birth weight; ETT: Endotracheal tube; MV: Mechanical ventilator CPAP continuous positive airway pressure; CDC: Center for disease control and prevention.
\end{abstract}

\section{Competing interests}

The authors declare that they have no competing interests.

\section{Authors' contributions}

SFA and HS designed the study and the tools, wrote the discussion, and submitted the manuscript. SS, WFE, MME, AGS, MA and WA performed education sessions and follow up rate of adherence of our unit team. AAA, $E A B$ and $M A B$ reviewed the results and the discussion and helped draft the manuscript. SMI, NEA, and NAS performed the statistical analysis, and wrote the discussion. TG collected samples and performed microbiology analysis. All authors read and approved the final manuscript.

\section{Acknowledgments}

The authors would like to thank the staff of the neonatal intensive care unit at the Zagazig University Children's Hospital for their collaboration. The authors would also like to thank the patients who participated in this study.

Received: 13 November 2014 Accepted: 27 July 2015

Published online: 06 August 2015

\section{References}

1. Center for Disease Control and Prevention. Criteria for Ventilator-associated pneumonia (VAP) Available at: Center. http://www.cdc.gov/nhsn/pdf/ pscmanual/protocol-updates.pdf.

2. Van der Zwet WC, Kaiser AM, van Elburg RM, Berkhof J, Fetter WP, Parlevliet $\mathrm{GA}$, et al. Nosocomial infections in a Dutch neonatal intensive care unit: surveillance study with definitions for infection specifically adapted for neonates. J Hosp Infect. 2005;61:300-11.

3. Gaynes RP, Edwards JR, Jarvis WR, Culver DH, Tolson JS, Martone WJ. Nosocomial infections among neonates in high-risk nurseries in the United States. Pediatrics. 1996;98:357-61.

4. Stoll BJ, Hansen NI, Adams-Chapman I, Fanaroff AA, Hintz SR, Vohr B, et al. National Institute of Child Health and Human Development Neonatal Research Network. Neurodevelopmental and growth impairment among extremely low birth weight infants with neonatal infection. JAMA. 2004;292:2357-65.

5. Al-Tawfiq JA, Abed MS. Decreasing ventilator-associated pneumonia in adult intensive care units using the Institute for Healthcare improvement bundle. Am J Infect Control. 2010;38:552-6.

6. Blamoun J, Alfakir M, Rella ME, Wojcik JM, Solis RA, Anees KM, et al. Efficacy of an expanded ventilator bundle for the reduction of ventilator-associated pneumonia in the medical intensive care unit. Am J Infect Control. 2009;37:172-5.

7. Foglia E, Meier MD, Elward A. Ventilator-associated pneumonia in neonatal and pediatric intensive care unit patients. Clin Microbiol Rev. 2007;20:409-25.

8. Apisarnthanarak A, Holzmann-Pazgal G, Hamvas A, Olsen MA, Fraser VJ. Ventilator-associated pneumonia in extremely preterm neonates in a neonatal intensive care unit: characteristics, risk factors, and outcomes. Pediatrics. 2003;112:1283-9.

9. Centers for Disease Control and Prevention (CDC). Guidelines for prevention of healthcare-associated pneumonia. MMWR Recomm Rep. 2004;53:1-36. 
10. American Thoracic Society Infectious Diseases Society of America. Guidelines for the management of adults with hospital-acquired, ventilatorassociated, and health care-associated pneumonia. Am J Respir Crit Care Med. 2005;171:388-416.

11. Kollef MH. Prevention of hospital-associated pneumonia and ventilator associated pneumonia. Crit Care Med. 2004;32:1396-405.

12. Resar R, Pronovost P, Haraden C, Simmonds T, Rainey T, Nolan T. Using a bundle approach to improve ventilator care processes and reduce ventilator-associated pneumonia. Jt Comm J Qual Patient Saf. 2005;31(5):243-8.

13. Lorente $L$, Blot $S$, Rello J. Evidence on measures for the prevention of ventilator-associated pneumonia. Eur Respir J. 2007;30:1193-207.

14. Omrane R, Eid J, Perreault MM, Yazbeck H, Berbiche D, Gursahaney A, et al. Impact of a protocol for prevention of ventilator-associated pneumonia. Ann Pharmacother. 2007:41:1390-6.

15. Gastmeier P, Geffers C. Prevention of ventilator-associated pneumonia: analysis of studies published since 2004. J Hosp Infect. 2007;67:1-8.

16. Ko“ksal N, Hacimustafao_glul M, Celebi S, Cüneyt Özakın. Nonbronchoscopic bronchoalveolar lavage for diagnosing ventilator-associated pneumonia in newborns. Turk J Pediatr. 2006;48:213-20.

17. Zafar N, Wallace CM, Kieffer P P, Schroeder P, Schootman M, Hamvas A. Improving survival of vulnerable infants increases intensive care nosocomial infection rate. Arch Pediat Adolesc Med. 2001;155:1098-104.

18. Garland JS. Strategies to prevent ventilator-associated pneumonia in neonates. Clin Perinatol. 2010:37:629-43.

19. Drakulovic MB, Torres A, Bauer TT, Nicolas JM, Nogué S, Ferrer M. Supine body position as a risk factor for nosocomial pneumonia in mechanically ventilated patients: a randomized trial. Lancet. 1999;354:1851-8.

20. Black S, LO E, Madriaga M et al. Nosocomial pneumonia in PICU. Abstract k-452. Presented at the 42nd interscience Conference on Antimicrobial Agents and Chemotherapy, Sept27-30, 2002, San Diego, Calif.

21. VanOgtrop ML, van Zoeren-Grobben D, Verbakel-Salomons EM, van Boven CP. Serratia marcescens in infections in neonatal departments: description of an outbreak and review of the literature. J Hosp Infect. 1997;36:95-103.

22. Szabó D, Filetóth Z, Szentandrássy J, Némedi M, Tóth E, Jeney C, et al. Molecular epidemiology of a cluster of cases due to Klebsiella pneumoniae producing SHV-5 extended-spectrum b- lactamase in the premature intensive care unit of a Hungarian hospital. J Clin microbial. 1999:37:4167-9.

23. Craven DE, Goularte TA, Make BJ. Contaminated condensate in mechanical ventilator circuits: a risk factor for nosocomial pneumonia? Am Rev Respir Dis. 1984;129:625-8.

24. Kawanishi F, Yoshinaga M, Morita M, Shibata T, Yamada T, Ooi Y, et al. Risk factors for ventilator-associated pneumonia in neonatal intensive care unit patients. J Infect Chemother. 2014;20:627-30.

25. Yuan TM, Chen LH, Yu HM. Risk factors and outcomes for ventilatorassociated pneumonia in neonatal intensive care unit patients. J Perinat Med. 2007;35:334-8.

26. Tan B, Zhang F, Zhang X, Huang YL, Gao YS, Liu X, et al. Risk factors for ventilator-associated pneumonia in the neonatal intensive care unit: a metaanalysis of observational studies. Eur J Pediatr. 2014;173:427-34.

27. Hentschel J, Brungger B, Studi K, Muhlemann K. Prospective surveillance of nosocomial infections in a Swiss NICU: low risk of pneumonia on nasal continuous positive airway pressure. Infection. 2005;33:350-5.

28. Holleman-Duray D, Kaupie D, Weiss MG. Heated humidified high-flow nasal cannula: use and a neonatal early extubation protocol. J Perinatol. 2007;27:776-81

29. Geffers C, Baerwolff S, Schwab F. Gastmeier. Incidence oh healthcareassociated infections in high-risk neonates: results from the German surveillance system for very-low-birth weight. J Hosp Infect. 2008;68:214-21.

30. Pineda LA, Saliba RG, El Solh AA. Effect of oral decontamination with chlorhexidine on the incidence of nosocomial pneumonia: a meta-analysis. Crit Care. 2006;10:R35

31. Chlebicki MP, Safdar N. Topical chlorhexidine for prevention of ventilatorassociated pneumonia: a meta-analysis. Crit Care Med. 2007;35:595-602.

32. Centers for Disease Control and Prevention. Ventilator-associated pneumonia (VAP) event, July 2013 CDC/NHSN protocol corrections, clarification and additions; 2013. http://www.cdc.gov/nhsn/PDFs/pscManual/ 6pscVAPcurrent pdf.

33. Dudeck MA, Horan TC, Peterson KD, Allen-Bridson K, Morrell G, Pollock DA, et al. National Healthcare Safety Network, data summary for 2010, deviceassociated module. Amer J Inf Control. 2011;39:798-816.
34. Rosenthal VD, Bijie H, Maki DG, Mehta Y, Apisarnthanarak A, Medeiros EA, Leblebicioglu H, Fisher D, Álvarez-Moreno C, Khader IA, Del Rocío González Martínez M, Cuellar LE, Navoa-Ng JA, Abouqal R, Guanche Garcell H, Mitrev Z, Pirez García MC, Hamdi A, Dueñas L, Cancel E, Gurskis V, Rasslan O, Ahmed A, Kanj SS, Ugalde OC, Mapp T, Raka L, Yuet Meng C, Thu le TA, Ghazal S, Gikas A, Narváez LP, Mejía N, Hadjieva N, Gamar Elanbya MO, Guzmán Siritt ME, Jayatilleke K; INICC members. Am J Infect Control. 2012 Jun;40(5):396-407.

35. Rosenthal VD, Maki DG, Salomao R, Moreno CA, Mehta Y, Higuera F, et al. Device-associated nosocomial infection in 55 intensive care units from 8 developing countries. Ann Inter Med. 2006;145:582-91.

36. Petdachai $\mathbf{W}$. Ventilator-associated pneumonia in a newborn intensive care unit. South east Asian J Trop Med Public Health. 2004;35:724-9.

37. Xie DS, Xiong W, Lai RP, Liu L, Gan XM, Wang XH, et al. Ventilator associated pneumonia in intensive care unit Hubei Province, China: a multicenter prospective cohort survey. J hosp Infect. 2011;78:284-8.

38. System CN. National Nosocomial Infection Surveillance (NNIS) System Report, data summary from January 1992-through June 2004, issued October 2004. Pediatrics. 2003;112:1283-9.

39. Raymond J, Aujard Y. Nosocomial infection in pediatric patients, a European multicenter prospective study, European Study Group. Infect Control Hosp Epidemiol. 2002;21:260-3.

40. Leroy $\mathrm{O}$, Soubrier S. Hospital- acquired pneumonia: risk factors, clinical features, management, and antibiotic resistance. Curr opin Pulm Med. 2004;10:171-5.

\section{Submit your next manuscript to BioMed Central and take full advantage of:}

- Convenient online submission

- Thorough peer review

- No space constraints or color figure charges

- Immediate publication on acceptance

- Inclusion in PubMed, CAS, Scopus and Google Scholar

- Research which is freely available for redistribution 